\title{
Rastelli operation for double outlet right ventricle, pulmonary atresia with ductal dependent pulmonary flow
}

\author{
Nirmal Panthee ${ }^{1}$, Sidhartha Pradhan ${ }^{1}$, Raamesh Koirala ${ }^{1}$, Bishow Pokhrel ${ }^{1}$, Deekshya Thapaliya ${ }^{1}$, \\ Apurba Thakur ${ }^{1}$, Ujjwal Jha ${ }^{1}$, Rabindra Timala ${ }^{1}$
}

${ }^{1}$ Department of Cardiac Surgery, Shahid Gangalal National Heart Center, Bansbari, Kathmandu, Nepal

Corresponding Author: Sidhartha Pradhan

Department of Cardiac Surgery, Shahid Gangalal National Heart Center,

Bansbari, Kathmandu, Nepal. Phone: 977-9851081163

Email: sidpradhan72@gmail.com

ORCID ID No: 0000-0001-5288-482X

Cite this article as: Panthee N., Pradhan S., Koirala R., et al. Rastelli operation for double outlet right ventricle, pulmonary atresia with ductal dependent pulmonary flow; Vol 18(2), 57-60.

Submission date: $22^{\text {nd }}$ June, 2021

Accepted date: $20^{\text {th }}$ August, 2021

\begin{abstract}
Double outlet right ventricle (DORV) with or without pulmonary atresia is a common indication for Rastelli operation. We very infrequently perform this surgery in our center. Here, we report a case of a ten-year-old girl who recently underwent Rastelli operation and patent ductus arteriosus (PDA) ligation for DORV, pulmonary atresia with ductal dependent pulmonary circulation by using custom-made valved conduit.
\end{abstract}

Keywords: Double outlet right ventricle, Pulmonary atresia, Rastelli operation

DOI: https://doi.org/10.3126/njh.v18i2.40406

\section{Introduction}

Rastelli operation refers to a generic phrase applied to the patients who undergo a surgery which includes a ventricular septal defect (VSD) closure with an extracardiac ventricle to pulmonary artery conduit1. This includes patients with truncus arteriosus, VSD with pulmonary atresia, double outlet right ventricle, and d-transposition of great arteries with pulmonary stenosis, among others ${ }^{1,2}$. This operation utilizes a conduit, valved or valveless. Alternative use of Ozaki technique for right ventricle- to- pulmonary artery conduit has been described by our Indian colleagues ${ }^{3}$. This operation is considered a complex operation and we very infrequently perform this procedure in our center. Here, we report a case of a ten-year-old girl who successfully underwent Rastelli operation in our center.

\section{Case report}

A ten-year-old girl was referred to us with history of bluish discoloration of lips since childhood. Her cardiac anomaly was diagnosed at the age of two months; however, her parents were reluctant to let her undergo surgery. Over time, her symptoms worsened with progressive bluish discoloration of her lips and shortness of breath of New York Heart Classification (NYHA) class III. She was therefore brought to our center for further evaluation.

On examination, she was playful and healthy-looking girl. Vitals were stable with blood pressure of $98 / 56 \mathrm{mmHg}$, temperature of $960 \mathrm{~F}$, respiratory rate of 22 per minute, and pulse of $116 \mathrm{bpm}$. Her $\mathrm{SpO} 2$ in room air was $74 \%$. Clubbing and cyanosis were present. However, there was no jugular venous distension, pedal edema, and hepatomegaly. She weighed $21 \mathrm{~kg}$ with body surface area (BSA) of $0.86 \mathrm{~m} 2$. 
Baseline hematologic and metabolic profiles were within normal limits except hemoglobin of $22.6 \mathrm{~g} \%$. Chest $\mathrm{X}$ ray showed cardiothoracic ratio (CTR) of 0.56 , with oligemic lung fields, and right ventricular hypertrophy (Figure 1A). ECG showed sinus rhythm of $97 \mathrm{bpm}, \mathrm{p}$ pulmonale, and right ventricular hypertrophy. Transthoracic echocardiography showed left ventricular end diastolic dimension (LVDd) of $2.7 \mathrm{~cm}$, left ventricular end systolic dimension (LVDs) of $1.9 \mathrm{~cm}$, left ventricular ejection fraction (EF) of $60 \%$. Pulmonary valve was atretic; with right pulmonary artery (RPA) measuring $1 \mathrm{~cm}$, left pulmonary artery (LPA) measuring $0.53 \mathrm{~cm}$ with proximal stenosis. Branch pulmonary arteries were confluent. Subaortic VSD measuring $1.8 \mathrm{~cm}$ was present with bidirectional shunt. Overriding of aorta was $50 \%$. Small atrial sepal defect was present with bidirectional shunt. There was a large patent ductus arteriosus (PDA) under the arch measuring $2.4 \mathrm{~mm}$ with left to right shunt. Peak pressure gradient across the PDA was $56 \mathrm{mmHg}$. Cardiac computed tomography (CT) scan confirmed all the echocardiography findings (Figure 1B, C, and D) except that there was minor discrepancy in the sizes of branch pulmonary arteries between $\mathrm{CT}$ scan and echocardiography, which is not unusual. Mc Goon ratio was 1.9 and Nakata index was $427 \mathrm{~mm} 2 / \mathrm{m} 2$.
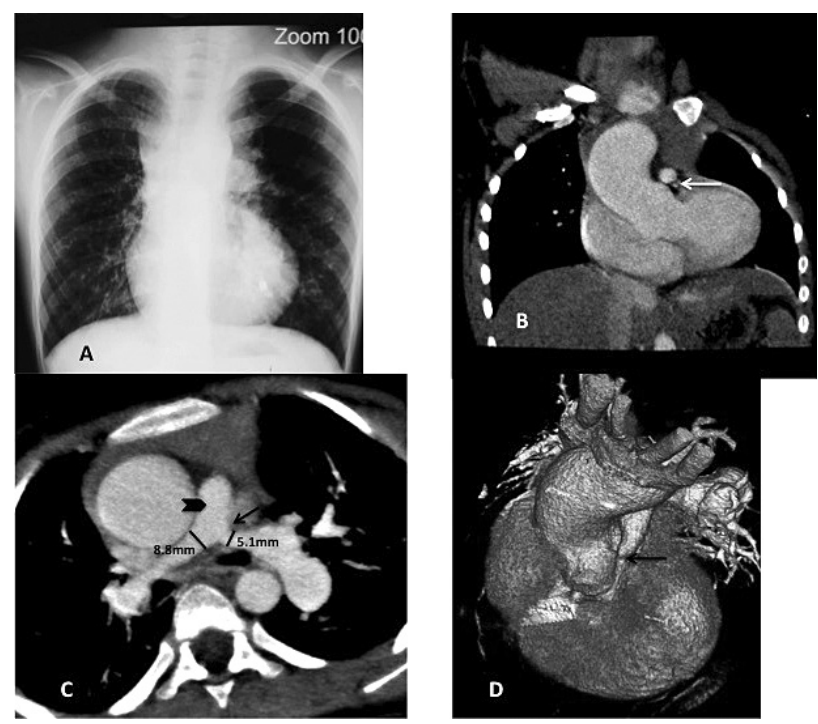

Figure 1. Preoperative imaging. A. Chest X-ray posteroanterior view showed CTR of 0.56, right ventricular hypertrophy, and oligemic lung fields. B. CECT scan coronal view showing narrow right ventricular outflow tract and atretic pulmonary valve (arrow). C. CECT scan axial view showing main PA (arrowhead), right PA measuring $8.8 \mathrm{~mm}$, left PA ostium measuring $5.1 \mathrm{~mm}$. Arrow shows left PA osteal stenosis. D. Three dimensionally reconstructed CECT image showing hypoplastic main PA (arrow). Abbreviations: CECT: contrast enhanced computed tomography; CTR: cardiothoracic ratio; PA: pulmonary artery.

Left heart catheterization showed left ventricular end diastolic pressure of $10 \mathrm{mmHg}$ with main pulmonary artery (MPA) pressure of $21 / 15 / 17 \mathrm{mmHg}$, RPA pressure of $20 / 14 / 17 \mathrm{mmHg}$, and distal LPA pressure of 19/13/16mmHg. PDA was seen under the arch supplying MPA and branch pulmonary arteries. Small major aortopulmonary collateral artery (MAPCA) supplying right lung was also noted.

With these, final diagnosis of double outlet right ventricle (DORV), pulmonary atresia, atrial septal defect, PDA dependent pulmonary circulation, LPA osteal stenosis was made, and she was planned for Rastelli procedure and PDA ligation.

With standard median sternotomy and central cannulation, cardiopulmonary bypass was established. Pulmonary valve annulus was severely hypoplastic with minimal forward flow. MPA was hypoplastic (Figure 2A). RPA was adequately sized. LPA had PDA inserted into it and was stenotic (Figure 2A) just lateral to the PDA insertion site with normal sized distal LPA. Right atrium (RA) was hypertrophied, small patent foramen ovale (PFO) was present. RV was severely hypertrophied with obliterated right ventricular outflow tract (RVOT) by hypertrophied crisscrossing RV muscle. Aorta was arising mostly from RV.
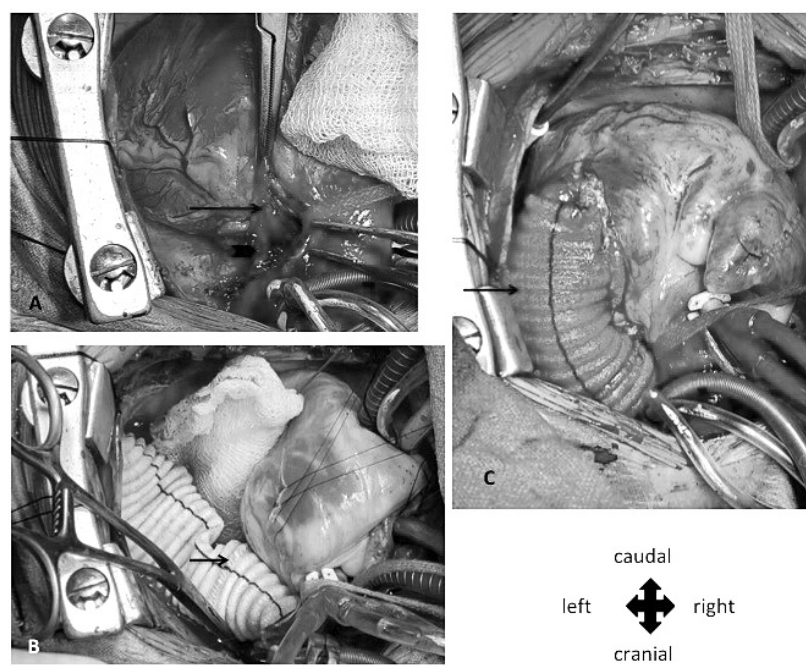

Figure 2. A. Intraoperative image showing atretic main pulmonary artery (arrow), and left pulmonary artery osteal stenosis (arrowhead). $B$. Custom-made valved conduit using $22 \mathrm{~mm}$ collagen coated vascular graft and 19mm Carpentier Edwards Perimount bioprosthesis. Arrow shows 4-0 prolene sewing the bioprosthesis inside the graft. C. Image after completion of proximal and distal anastomosis of valved conduit (arrow).

After careful dissection of RPA and LPA, PDA was skeletonized and doubly ligated. Left atrial vent tube was inserted via PFO. Expanded polytetrafluoroethylene (ePTFE) patch closure of VSD was done using 6-0 prolene running suture. During this time, a customized bio valved conduit was made using $19 \mathrm{~mm}$ Carpentier Edwards Perimount bioprosthesis (Edwards Lifesciences Corporation) and $22 \mathrm{~mm}$ collagen coated knitted polyester vascular prosthetic graft (Intervascular, La Ciotat, France) on back table by two surgeons (Figure 2B). MPA was transected and its proximal end was oversewn. The distal end of MPA was splayed with incision extending into LPA beyond the stenotic segment. The distal end of valved conduit was anastomosed with the splayed MPA/LPA using 6-0 prolene. Right ventriculotomy was made and the proximal end of the valved conduit was anastomosed with the right ventriculotomy using 5-0 prolene, buttressed with PTFE felt strip. Upon completion of both proximal and distal sutures, bioglue was applied over the suture lines. Tricuspid valve was repaired by apposing septal leaflet with anterior leaflet. After careful deairing and PFO closure, right atrium was closed. Aortic cross clamp was removed. She was weaned off cardiopulmonary bypass uneventfully. Final schema of completed conduit anastomosis is shown in Figure 2C. Total cardiopulmonary bypass (CPB) time was 249 minutes, aortic cross clamp (AoX) time was 160 minutes. Ten minutes of modified ultrafiltration (MUF) was employed, which was followed by decannulation. Hemostasis was difficult, so we decided to do gauze packing and transfer the patient to pediatric intensive care unit (PICU). With two pieces of gauze put inside, sternum and skin were closed, and she was transferred to PICU with minimal doses of dopamine, milrinone, GTN, adrenaline, and noradrenaline. Overnight her vitals were stable in PICU with minimal chest tube drainage. So, decision was made to remove the gauzes on postoperative day 1 (POD1), which happened to be 15 hours after arrival to PICU. 
Upon opening the chest for removal of gauze, hemostasis was good. Closure was done in usual fashion. Usual ICU care was provided, with gradual tapering of inotropes. She was extubated on POD2 (total ventilatory hours: 38 hours). Mediastinal chest tube was removed on POD5, and pleural chest tubes were removed on POD7. She was transferred to general ward on POD7. In the general ward, she developed infection at the right femoral puncture site which was accessed during preoperative left heart catheterization. Klebsiella pneumoniae was isolated from the groin wound swab, which was treated by multiple saline irrigations, injectable imipenem, followed by secondary closure using interrupted prolene sutures on POD19. Postoperative echocardiography on POD27 revealed left ventricular EF of $60 \%$, minimal leak across VSD closure site, no leak across PDA site, trace tricuspid regurgitation, peak pressure gradient across the RVOT conduit site of $6 \mathrm{mmHg}$ with trace conduit valve regurgitation. Pre-discharge ECG showed sinus rhythm of $133 \mathrm{bpm}$, right ventricular hypertrophy, with newly developed right bundle branch block. Postoperative CT scan done on POD28 showed nicely seated conduit and no stenosis of osteal left PA. The size of the RPA had increased to $11.6 \mathrm{~mm}$ from $8.8 \mathrm{~mm}$ and that of LPA had increased to $10.3 \mathrm{~mm}$ from $5.1 \mathrm{~mm}$ compared with preoperative CT scan measurements (Figure 3). After completion of the course of imipenem, and removing the prolene sutures in her groin, she was discharged home on POD30 with INR of 2.3 on warfarin $2 \mathrm{mg}$ OD. At the time of discharge, her $\mathrm{SpO} 2$ was $98 \%$ in room air.

\section{Discussion}

Gian Carlo Rastelli reported first successful case in clinical application of Rastelli operation in a five-and half-year old boy with type II truncus arteriosus on September 8, 19674. Previously, his team had shown success in animal experiments; however, clinical application had failed twice before this became a success story ${ }^{4}$. Today, this operation is widely utilized by congenital cardiac surgeons worldwide. VSD is baffled in a way that aorta arises from left ventricle and the continuity from right ventricle to pulmonary artery is achieved by utilizing an extracardiac conduit, which results into biventricular repair in hearts that would have been deemed unsuitable for biventricular repair earlier.

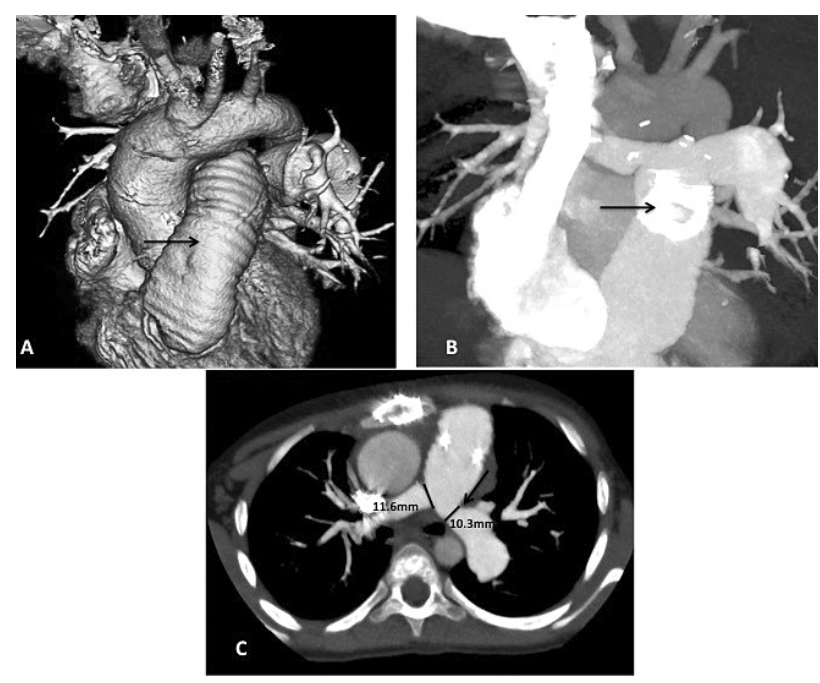

Figure 3. Postoperative imaging. A. 3-D reconstructed CECT image showing nicely seated valved conduit (arrow) between right ventricle and pulmonary artery. B. Coronal view of CECT image showing the valve (arrow) inside the conduit. Note that the valve is kept close to the pulmonary confluence as opposed to the right ventricle. C. Axial view CECT showing growth of both right PA $(11.6 \mathrm{~mm})$ and left $P A(10.3 \mathrm{~mm})$. Arrow shows the site of preoperative left PA osteal stenosis. Please compare this image with Figure 1C. Abbreviations: CECT: contrast enhanced computed tomography; PA: pulmonary artery.
Pulmonary flow is restored after Rastelli procedure by using an extracardiac conduit. The conduit may be valved or valveless; although valved conduit is always preferred to prevent free pulmonary regurgitation. Conduit type and material is always debatable. Contegra bovine jugular valved conduit, homograft, Ozaki type valved conduit, or handmade trileaflet ePTFE valved conduit are utilized for pulmonary reconstruction during Rastelli operation $^{3,5,6}$. Contegra conduits and homografts almost always require redo surgery for conduit exchange due to calcification and degeneration during long term follow up. A Japanese group has reported the use of ePTFE membrane to create three cusps in a conduit, and they claim that this conduit is more durable, less costly, and readily available as opposed to Contegra conduit or homograft6. We do not have Contegra valved conduit and homograft in our center. The thin ePTFE membrane utilized to make trileaflet conduit is not available in our center either. So, the only viable way for us would be to hand-sew a bioprosthetic valve inside a conduit. Degeneration of bioprosthesis is always an issue and we believe our patient will require conduit replacement in the years to come.

A Korean group has described the long term results of Rastelli operation with a mechanical valve ${ }^{7}$. Out of 20 patients, none of the patients had thromboembolism or anticoagulation-related complications. However, six patients required early reoperation for prosthetic valve failure due to pannus formation or thrombosis; and nine patients required late reoperation for Dacron conduit stenosis at the anastomotic site. Freedom from reoperation at 5 years and 10 years was $53 \%$ and $37 \%$, respectively ${ }^{7}$.

Obtaining perfect hemostasis after cardiac surgery is sometimes difficult which demands gauze packing. Open chest management in these patients is not so uncommon. This is a good judgement call in part of the operating surgeon with aim of limiting blood loss and avoiding blood products transfusion. Due to the stable immediate postoperative course and evidence of minimal bleeding, we were able to remove the packed gauze on POD1. Antegrade flow from right ventricle to pulmonary circulation is essential for maintenance of normal saturation level, as well as for the growth of branch pulmonary arteries. Our patient showed significant growth of both right and left PAs in the CT scan obtained 4 weeks postoperatively; and she had normal levels of peripheral oxygen saturation before discharge.

Despite the good short and long term results following Rastelli operation, many patients will have to deal with the surgical sequalae such as right ventricular outflow tract obstruction, pulmonary regurgitation, residual VSD, so that reintervention in some forms will be required for most patients ${ }^{8}$. Our patient had good biventricular function prior to discharge with very minimal gradient across the valved conduit. We believe that minimal leak across VSD closure site will disappear during follow up; if not, she might be a candidate of device closure during subsequent follow up as reported by Giardini and colleagues who have successfully closed the residual VSD closure 13 years after Rastelli operation in a 17-year-old patient9. Long hospital stay in our patient was partly due to the infection of her right groin and partly due to some social reason during the COVID-19 pandemic.

\section{Conclusion}

We report a successful management of a case of Rastelli operation for DORV and pulmonary atresia in our center. This operation can be done with hand-sewn valved conduit, to avoid patient being subjected to single ventricle pathway, which has much more complications with worse quality of life compared to biventricular repair.

\section{Conflicts of interests \\ None \\ Acknowledgement \\ None}




\section{References}

1. Backer CL, Mavroudis C. The Rastelli operation. Operative techniques in Thoracic and Cardiovascular Surgery 2003;8(3):121-130. DOI: https://doi.org/10.1053/S15222942(03)00034-7

2. Sano S, Karl TR, Mee RBB. Extracardiac valved conduits in the pulmonary circuit. Annals of Thoracic Surgery 1991; 52:285-290. DOI: https://doi.org/10.1016/00034975(91)91354-X

3. Raju V, Padmanabhan C, Baird CW. Alternative uses of the Ozaki technique: Aortic valved conduit in a Bentall operation and right ventricle-to-pulmonary artery conduit. World Journal for Pediatric and Congenital Heart Surgery 2021;12(3):406410. DOI: https://doi.org/10.1177/2150135121995461

4. McGoon DC, Rastelli GC, Ongley PA. An operation for the correction of truncus arteriosus. Journal of American Medical Association 1968;205(2):69-73. DOI: https://doi.org/10.1001/ jama.1968.03140280023007

5. Urso S, Rega F, Meuris B, Gewillig M, Eyskens B, Daenen $\mathrm{W}$, et al. The Contegra conduit in the right ventricular outflow tract is an independent risk factor for graft replacement. European Journal of Cardiothoracic Surgery 2011; 40:603609. DOI: https://doi.org/10.1016/j.ejcts.2010.11.081

6. Ando M, Takahashi Y. Ten-year experience with handmade trileaflet polytetrafluoroethylene valved conduit used for pulmonary reconstruction. Journal of Thoracic and Cardiovascular Surgery 2009; 137:124-131. DOI: https://doi. org/10.1016/j.jtcvs.2008.08.060

7. Choi SH, Kim WH, Kim KC, Kwak JG, Kim CY, Lee JR, et al. Long term results of Rastelli operation with a mechanical valve. Korean Journal of Thoracic and Cardiovascular Surgery 2006; 39:900-905.

8. Vouhe PR, Tamisier D, Leca F, Ouaknine R, Vernant F, Neveux JY. Transposition of the great arteries, ventricular septal defect, and pulmonary outflow tract obstruction: Rastelli or Lecompte procedure? Journal of Thoracic and Cardiovascular Surgery 1992; 103:428-436. DOI: https://doi. org/10.1016/S0022-5223(19)34981-5

9. Giardini A, Donti A, Gargiulo G, Formigari R, Bonvicini M, Picchio FM. Transcatheter residual ventricular septal defect closure after Rastelli operation. Catheterization and Cardiovascular Interventions 2005; 64:209-212. DOI: https:// doi.org/10.1002/ccd.20250 